\title{
Leer y escribir en contextos académicos: Géneros, Corpus y Métodos
}

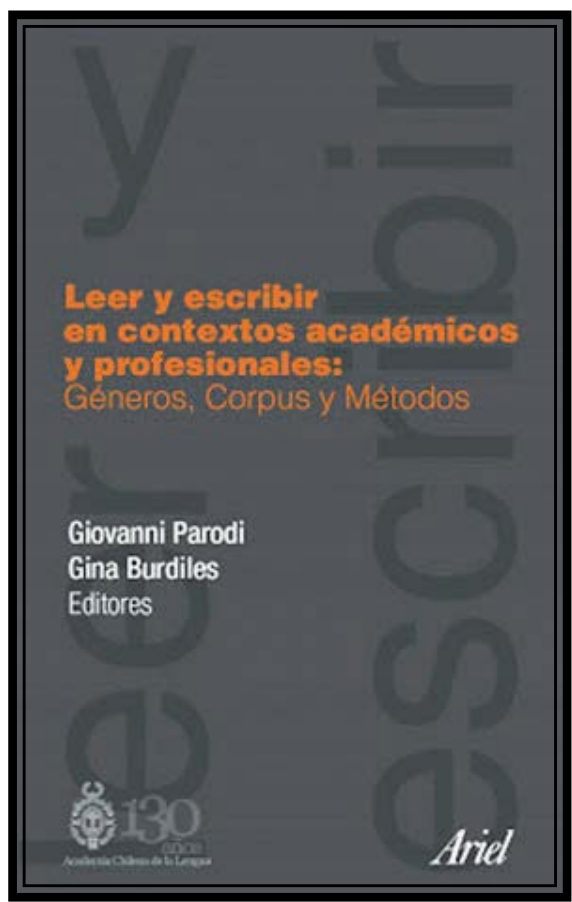

Giovanni Parodi \& Gina Burdiles (eds.) (2015). Leer y escribir en contextos académicos: Géneros, Corpus y Métodos. Santiago de Chile: Ariel.

[...] En términos generales, algunos aportes que hemos incluido bajo el título de este libro dicen relación con que en la mayoría de estas investigaciones se adopta una perspectiva desde la lingüística del corpus y se busca analizar amplias muestras de textos, con el fin de producir resultados empíricos robustos y alcanzar hallazgos significativos. Al mismo tiempo, en cada capítulo se han hecho esfuerzos por describir de manera lo más detallada posible los métodos empleados, esperando aportar tanto a la replicabilidad de estas investigaciones como a un propósito didáctico. También se ha intentado cubrir una amplia gama de disciplinas, tanto de las ciencias sociales y humanidades como de las ciencias básicas.

Ahora bien, en términos formales, el presente volumen está conformado por trece capítulos, divididos encuatro partes[...]Enla primera parte, se reúne a los primeros cinco capítulos, los cuales convergen en su preocupación por identificar y describir un conjunto de géneros discursivos que permiten el acceso y la construcción de conocimientos especializados y/o permiten la comunicación en ciertas disciplinas, tanto en ámbitos académicos universitarios, a nivel de pregrado y postgrado, como en contextos profesionales [...] La segunda parte del libro está compuesta por dos investigaciones que estudian algunos de los géneros que permiten a los estudiantes universitarios acreditar sus conocimientos en el proceso de formación académica y de incorporación a sus comunidades discursivas [...] Los siguientes cuatro capítulos conforman la tercera parte del libro. Todos ellos son el producto de una fructífera línea de trabajo que, durante los últimos años y a través de diversos proyectos de investigación, ha venido contribuyendo a aportar marcos teóricos 
y hallazgos empíricos acerca de los rasgos multisemióticos de los géneros académicos y profesionales $[\ldots]$

La tercera parte del libro, en directa relación con los capítulos precedentes de este apartado, se cierra con un interesante viraje hacia la comprensión de textos escritos multisemióticos, considerando su carácter multimodal [...] La cuarta parte y final de este volumen se ocupa de ciertos aspectos lexicogramaticales que, a partir del examen de varios corpora, permiten dar cuenta de rasgos específicos de algunos géneros académicos y profesionales pertenecientes a varias disciplinas.

De la introducción del libro, pp. 15-23. 